Conclusion: Prevalence of axial involvement in our cohort $(35,2 \%)$ is found within the data reported in other studies (25-70\%). Nevertheless, we found less prevalence of HLAB27 positive than other reports. Patients with HLAB27 positive, dactylitis or uveitis are diagnosed at earlier ages.

Disclosure of Interests: None declared

DOI: 10.1136/annrheumdis-2020-eular.6270

\section{AB0829 INFLAMMATORY BOWEL DISEASE IN PSORIATIC ARTHRITIS. STUDY OF 306 PATIENTS FROM A SINGLE UNIVERSITARY CENTER. PREVALENCE, CLINICAL FEATURES AND RELATIONSHIP TO BIOLOGIC THERAPY.}

L. Sanchez-Bilbao ${ }^{1}$, D. Martinez-Lopez ${ }^{1}$, N. Palmou-Fontana ${ }^{1}$, S. Armesto ${ }^{2}$ M. A. González-Gay', R. Blanco'. ' H.U. Marqués de Valdecilla, Rheumatology, Santander, Spain; ${ }^{2}$ H.U. Marqués de Valdecilla, Dermatology, Santander, Spain

Background: Inflammatory bowel disease (IBD), which includes Crohn's disease (CD), Ulcerative colitis (UC), and undetermined colitis may be related to psoriasis and psoriatic arthritis (PsA). Biologic therapy (BT) is useful in PsA and IBD but paradoxically has been related to IBD.

Objectives: In a wide series of PsA, our aim was to assess a) the epidemiologi$\mathrm{cal}$ and clinical features of associated IBD and $\mathbf{b}$ ) its relationship with BT.

Methods: All unselected consecutive patients studied in a single reference University Hospital with: a) PSA (CASPAR criteria) and b) IBD: CD, UC and undetermined colitis diagnosed by endoscopic patterns, clinical criteria and laboratory tests. A comparative study between patients with and without IBD was performed

Results: We studied 306 (165 women/141 men) patients with PsA; mean age at PsA diagnosis of $41.7 \pm 15.79$ years; delay of diagnosis from the onset of symptoms of 2.6 \pm 2.01 years. IBD $(\mathrm{CD}=6 ; \mathrm{UC}=1$ and undetermined colitis=3) was observed in 10 of 306 (3.3\%, 8 women/2 men). A significant more frequency of enthesitis, positive HLA-B27 and non-significant more severe PsA (axial, and hip involvement, and a higher BASDAI, BASFI, DAPSA, PASI) was observed in patients with associated-IBD (TABLE).

IBD was present before PSA in 5 patients and in the other 5 , after $9.6 \pm 15.3$ years of evolution of PsA. BT for PsA has been used in $1(20 \%)$ (etanercept) of these 5 patients which developed IBD and in 67 of $296(22.6 \%)$ without IBD (Adalimumab 45; Certolizumab 8; Infliximab 6; Golimumab 4; Etanercept 4).

Conclusion: IBD in PsA was uncommon (3.3\%), may be associated to a more severe PsA, and no relationship to BT was found.

TABLE 1.

\begin{tabular}{|c|c|c|c|}
\hline & $\begin{array}{l}\text { Patients with IBD } \\
\qquad(n=10)\end{array}$ & $\begin{array}{l}\text { Patients without IBD } \\
\qquad(\mathrm{n}=296)\end{array}$ & $\mathbf{p}$ \\
\hline \multicolumn{4}{|l|}{ DEMOGRAPHIC PARAMETERS } \\
\hline Sex, $\mathrm{n}(\%)$ & 2 o/8 우 (20.0/80.0) & 139 o & $p=0.11$ \\
\hline $\begin{array}{l}\text { Age at PsA symptoms onset } \\
\text { (years), mean } \pm \text { SD }\end{array}$ & $39.0 \pm 15.1$ & $44.2 \pm 11.4$ & $p=0.17$ \\
\hline Age at PsA diagnosis, mean \pm SD & $41.7 \pm 15.7$ & $46.4 \pm 15.8$ & $p=0.22$ \\
\hline \multicolumn{4}{|l|}{$\begin{array}{l}\text { PsA RELATED DATA } \\
\text { PsA type }\end{array}$} \\
\hline Asymmetric Oligoarticular, n (\%) & $4.0(40.0)$ & $159(53.7)$ & $p=0.59$ \\
\hline Symmetrical Polyarthritis, n (\%) & $0.0(0.0)$ & $46(15.5)$ & $p=0.37$ \\
\hline Axial, n (\%) & $3.0(30.0)$ & $40(13.5)$ & $p=0.31$ \\
\hline Mixed, n (\%) & $3.0(30.0)$ & $51(17.2)$ & $p=0.54$ \\
\hline Enthesitis, n (\%) & $7.0(70.0)$ & $111(37.5)$ & $p=0.03^{*}$ \\
\hline Dactylitis, n (\%) & $0.0(0.0)$ & 79 (26.7) & $p=0.70$ \\
\hline Hip involvement $\mathrm{n}(\%)$ & $4.0(40.0)$ & 55 (18.5) & $p=0.57$ \\
\hline \multicolumn{4}{|l|}{ Scores } \\
\hline BASDAI, median [ICR] & $3.1[0.0-4.4]$ & $2.2[0.0-4.5)$ & $p=0.64$ \\
\hline BASFI, median [ICR] & $6.0[0.0-6.9]$ & $0.0[0.0-3.3]$ & $p=0.69$ \\
\hline DAPSA, median [ICR] & $10.7[0.0-14.62]$ & $4.3[0.0-13.0]$ & $p=0.31$ \\
\hline PASI, median [ICR] & $2.3[0.0-6.7]$ & $0.6[0.0-2.38]$ & $p=0.70$ \\
\hline Laboratory tests: HLA-B27, n (\%) & $6.0(60.0)$ & $23(7.8)$ & $p=0.001^{\star}$ \\
\hline
\end{tabular}

Disclosure of Interests: Lara Sanchez-Bilbao Grant/research support from: Pfizer, David Martinez-Lopez: None declared, Natalia Palmou-Fontana: None declared, Susana Armesto: None declared, Miguel A González-Gay Grant/ research support from: Pfizer, Abbvie, MSD, Speakers bureau: Pfizer, Abbvie, MSD, Ricardo Blanco Grant/research support from: AbbVie, MSD, and Roche, Speakers bureau: AbbVie, Pfizer, Roche, Bristol-Myers, Janssen, and MSD DOI: 10.1136/annrheumdis-2020-eular.4806

\section{AB0830 LIPID PROFILE IN PSORIATIC ARTHRITIS. FREQUENCY AND ASSOCIATION WITH DISEASE ACTIVITY.}

V. Savio ${ }^{1,2}$, Y. Tissera ${ }^{1}$, M. I. Quaglia ${ }^{1}$, J. A. Albiero ${ }^{1}$, C. G. Alonso ${ }^{1}$ M. Demarchi' ${ }^{1}$, C. Maldini ${ }^{2}$, C. Gobbi ${ }^{1,2}$, M. Yorio $^{1,2}$, A. C. Martini ${ }^{2}$, M.

E. Castrillon ${ }^{3}$, P. Alba $^{1,2}{ }^{1}$ Hospital Córdoba, Córdoba, Argentina; ${ }^{2}$ Universidad Nacional de Cordoba, Córdoba, Argentina; ${ }^{3}$ Hospital Italiano de Cordoba, Cordoba, Argentina

Background: Psoriatic arthritis (PsA) is a chronic inflammatory disease associated with higher risk of cardiovascular events and metabolic syndrome. The inflammation not only accelerates atherosclerosis, but also may influence cardiovascular $(\mathrm{CV})$ risk factors such as lipid profile, blood pressure and insulin resistance. Lipid profile has previously been studied in PsA, however this association is still controversial.

Objectives: To study the frequency of altered lipid profile in patients with PsA and its association with disease activity.

Methods: We studied all the patients with diagnosis of PsA who consecutively attended to Rheumatology Unit at Cordoba Hospital from July 2018 to December 2019. PsA was diagnosed according CASPAR criteria. Clinical and laboratory data were collected. The activity of the disease was evaluated by PASI, MDA and DAPSA. Quantitative variables will be expressed in median and 1st and 3rd interquartile; qualitative variables expressed in frequency and percentage. Correlation analysis was calculated using Spearman's rank correlation coefficient. $\mathrm{P}<0.05$ was considered statistically significant.

Results: 42 PsA patients were included. Mean age was 56 years old $(47.25-62.75)$ and $54.76 \%$ were female $(n=23) .92 .86 \% \quad(n=39)$ of the patients had plaque Psoriasis and $87.8 \%(n=36)$ had peripheral joint involvement.

Frequency of comorbidities in PsA are shown in Graphic 1. 31 (73.8\%) of the patients were treated with topical therapy, $3(7.14 \%)$ with phototherapy, $31(73.8 \%)$ with Methotrexate and $17(41.46 \%)$ with biologics and JAK inhibitor. Activity Disease Index and Lipid profile are shown in Table 1 and 2 .

There was not association between Apo B/Apo A coefficient with DAPSA (rho=0.013; $\mathrm{p}=0.940$ ) and MDA (rho=-0.029; $\mathrm{p}=0.867$ ).

Conclusion: In spite of the presence of cardiovascular factors in the majority of PsA patients, lipid profile is not correlated with disease activity in this population.

References:

[1] Ahlehoff O, Gislason GH, Charlot M, et al. Psoriasis is associated with clinically significant cardiovascular risk: A Danish nationwide cohort study. $J$ Intern Med 2011:270:147-57.

[2] Mallbris, L., Ritchlin, C.T., Ståhle, M. "Metabolic disorders in patients with psoriasis and psoriatic arthritis." Curr RheumatolRep.8(5): 355-363. 2006

[3] Ng CY, Tzeng I-S, Liu S-H, Chang Y-C, Huang Y-H. Metabolic parameters in psoriatic patients treated with interleukin-12/23 blockade (Ustekinumab). J Dermatol 2018; 45:309-313

[4] Kaur S, Kingo K, Zilmer M. Psoriasis and cardiovascular risk - do promising new biomarkers have clinical impact? Mediators Inflamm 2017; 2017 : 7279818

[5] Gentile M, Peluso R, Di Minno MN, et al. Association between small dense LDL and sub-clinical atherosclerosis in patients with psoriatic arthritis. ClinRheumatol 2016; 35: 2023-9.

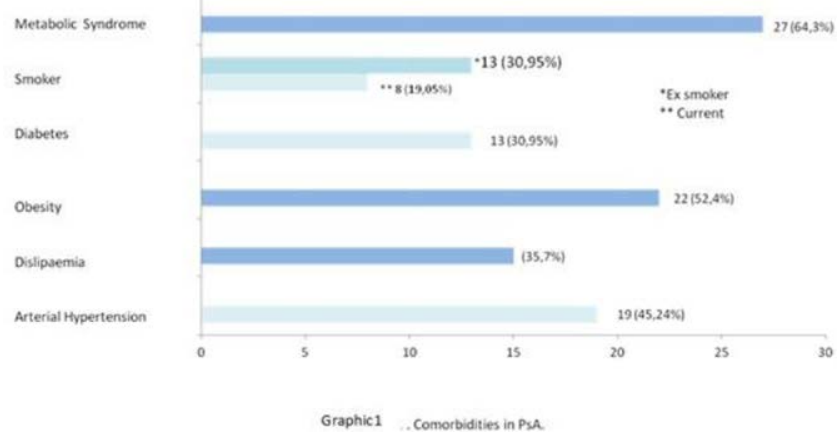

Graphic 1. Comorbidities in PsA 
Table. 1. Activity Disease Index in PsA

\begin{tabular}{lc}
\hline ACTIVITY INDEX & $\mathbf{n = 4 2}$ \\
\hline DAPSA & $14.45(9.72-23.92)$ \\
DAPSA & 3 \\
$\leq 4$ REMISSION & 16 \\
$>4$ y 14 low disease activity & 17 \\
$>14$ y 28 moderate disease activity & 3 \\
$>28$ high disease activity & $14.00(8.00-23.00) / 41^{*}$ \\
cDAPSA & $9(25) / 36$ \\
MDA & $2.20(0.20-6.80) / 41^{*}$ \\
PASI & \\
& ${ }^{*}$ Expressed in median and interquartiles.Qualitative variables expressed in frequency and \\
percentage. &
\end{tabular}

Table. 2. Lipid Profile in PsA patients.

\begin{tabular}{lc}
\hline Cholesterol (mg/dl) & $194.5(164.8-218.2)$ \\
HDL (mg/dl) & $48.00(37.00-57.00)$ \\
LDL (mg/dl) & $114.5(78.5-140.8)$ \\
TG (mg/dl) & $139.50(89.25-191.20)$ \\
\hline
\end{tabular}

Expressed in median and interquartiles.

Disclosure of Interests: None declared

DOI: 10.1136/annrheumdis-2020-eular.2185

\section{AB0831 COMPARISON OF DIFFERENT REMISSION INDICES IN PATIENTS WITH PSORIATIC ARTHRITIS: A POST HOC ANALYSIS OF DATA FROM PHASE 3 TOFACITINIB STUDIES}

E. Schneeberger ${ }^{1}$, G. Citera ${ }^{1}$, P. Nash ${ }^{2}$, J. S. Smolen ${ }^{3}$, P. J. Mease ${ }^{4}$ E. Soriano ${ }^{5}$, C. Helling ${ }^{6}$, A. E. Szumski ${ }^{7}$, R. Mundayat ${ }^{8}$, D. Graham ${ }^{9}$, D. Ponce de Leon ${ }^{10} .{ }^{1}$ Instituto de Rehabilitación Psicofísica, Buenos Aires, Argentina; ${ }^{2}$ Griffith University, Brisbane, Australia; ${ }^{3}$ Medical University of Vienna, Vienna, Austria; ${ }^{4}$ Swedish Medical Center and University of Washington, Seattle, United States of America; ${ }^{5}$ Hospital Italiano de Buenos Aires, Buenos Aires, Argentina; ${ }^{6}$ Pfizer Inc, Buenos Aires, Argentina; ${ }^{7}$ Pfizer Inc, Collegeville, United States of America; ${ }^{8}$ Pfizer Inc, New York, United States of America; ${ }^{9}$ Pfizer Inc, Groton, United States of America; ${ }^{10}$ Pfizer Inc, Lima, Peru

Background: An international task force has agreed that remission and low disease activity (LDA) are treatment targets for patients (pts) with PsA, and recommends the Disease Activity Index in Psoriatic Arthritis (DAPSA) and minimal disease activity (MDA) to assess disease activity states. ${ }^{1}$ Tofacitinib is an oral Janus kinase inhibitor for the treatment of PsA.

Objectives: In this post hoc analysis, we compared DAPSA LDA with MDA, and DAPSA remission with very low disease activity (VLDA) and DAS28-3(CRP) remission, in pts with PsA receiving tofacitinib.

Methods: Data were pooled from 2 Phase 3 studies (OPAL Broaden [12 months; NCT01877668]; OPAL Beyond [6 months; NCT01882439]) for pts receiving tofacitinib 5 or $10 \mathrm{mg}$ twice daily (BID) or placebo (PBO). DAPSA was determined by summing: swollen joint count (SJC66); tender/painful joint count (TJC68); Patient's Global Assessment of Arthritis (PtGA; visual analogue scale [VAS]); pain (VAS); and CRP. Pts were classified as achieving MDA or VLDA when meeting $\geq 5$ (MDA) or 7 (VLDA) of the following criteria: TJC68 $\leq 1$; SJC6 $\leq 1$; Psoriasis Activity and Severity Index $\leq 1$ or body surface area $\leq 3 \%$; pain (VAS) $\leq 15$; PtGA (VAS) $\leq 20 ; \mathrm{HAQ}-\mathrm{DI} \leq 0.5$; tender entheseal points (using Leeds Enthesitis Index [LEI]) $\leq 1$. A logistic regression model was used to assess demographic and baseline characteristics as predictors of a trend in DAPSA scores at Month (M)3. DAPSA LDA ( $\leq 14)$, MDA, DAPSA remission (DAPSA $\leq 4$ ), VLDA and DAS28-3(CRP) remission (DAS28-3[CRP]<2.6) rates were compared at $\mathrm{M} 1, \mathrm{M} 3$ and $\mathrm{M} 6$ for pts receiving tofacitinib $5 \mathrm{mg}$ BID and at M6 for pts receiving tofacitinib 5 or $10 \mathrm{mg} \mathrm{BID.} \mathrm{Agreement} \mathrm{between}$ disease activity indices at M6 was evaluated using a kappa test. The percentage of tofacitinib-treated pts who achieved MDA, VLDA and non-response was reported at M6, stratified by achievement of DAPSA LDA, remission or non-response.

Results: This analysis included 709 pts: tofacitinib $5 \mathrm{mg} \mathrm{BID,} n=237$; tofacitinib $10 \mathrm{mg} \mathrm{BID}, \mathrm{n}=236 ; \mathrm{PBO}, \mathrm{n}=236$. At $\mathrm{M} 3$, older patients treated with tofacitinib, and tofacitinib- or PBO-treated pts with higher baseline SJC66, TJC68, PtGA VAS, HAQ-DI, LEI and Pain VAS, were significantly $(p<0.05)$ more likely to have higher DAPSA. DAPSA LDA, MDA, remission (DAPSA and DAS28-3[CRP]) and VLDA rates generally increased from $M 1$ to $M 6$ for patients receiving tofacitinib $5 \mathrm{mg}$ BID (Figure a). At M6, most tofacitinib-treated pts who achieved MDA, and all who achieved VLDA, were also in DAPSA remission or LDA (Figure b). At least moderate agreement (defined by kappa values 0.41-0.60) was observed between DAPSA LDA and MDA, and between DAPSA remission and VLDA, with both doses of tofacitinib at M6 (Figure c).

Conclusion: Remission and LDA rates generally increased over time in pts with PsA receiving tofacitinib. DAPSA LDA showed moderate agreement with MDA, and DAPSA remission showed at least moderate agreement with VLDA, confirming that DAPSA and MDA are useful measurement tools to assess disease activity in pts with PsA treated with tofacitinib.

References:

[1] Smolen et al. Ann Rheum Dis 2018;77:3-17.

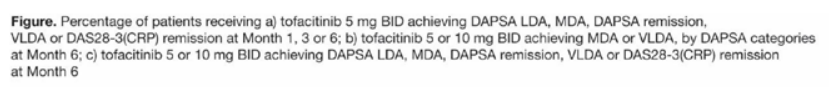
at $M$

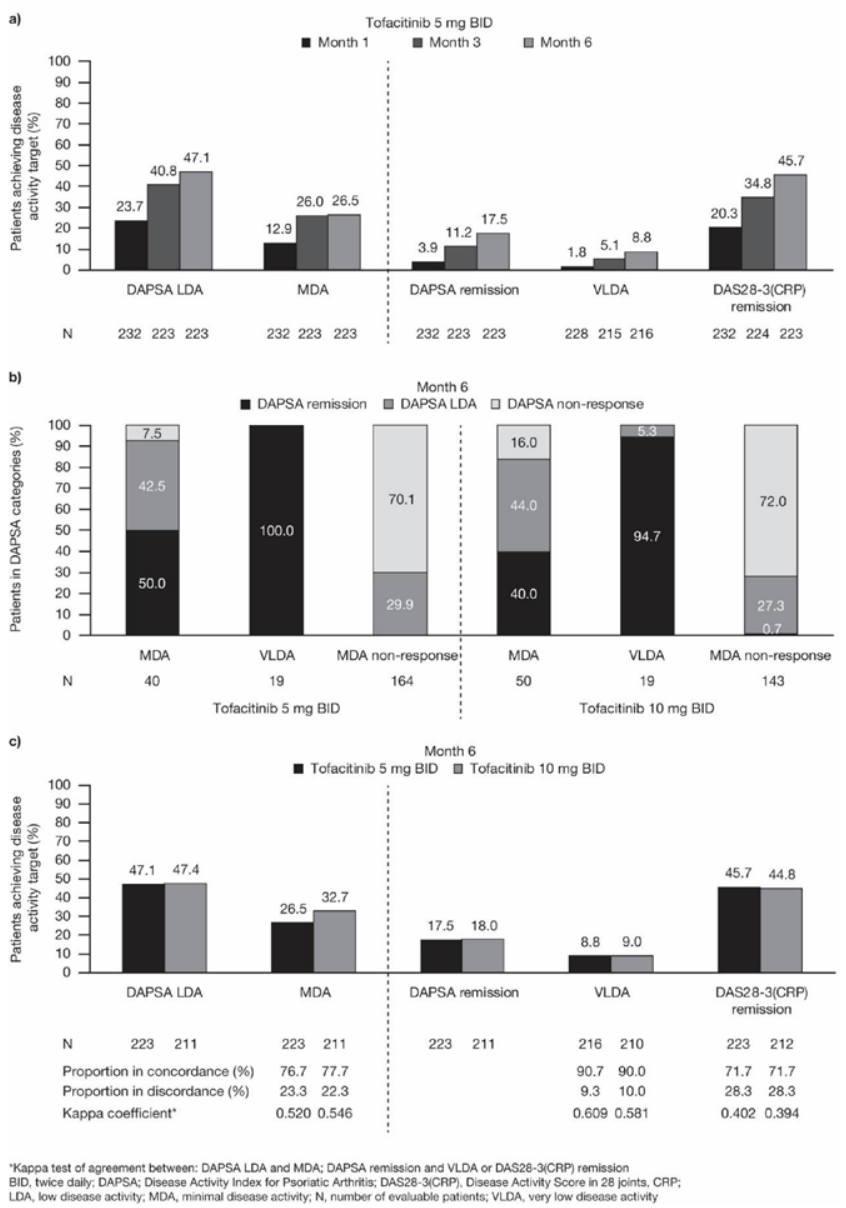

Acknowledgments: Study sponsored by Pfizer Inc. Medical writing support was provided by Sarah Piggott of CMC Connect, McCann Health Medical Communications, and funded by Pfizer Inc.

Disclosure of Interests: Emilce Schneeberger: None declared, Gustavo Citera Grant/research support from: AbbVie, Amgen, Eli Lilly, Gema, Genzyme, Novartis and Pfizer Inc, Consultant of: AbbVie, Amgen, Eli Lilly, Gema, Genzyme, Novartis and Pfizer Inc, Peter Nash Grant/research support from: AbbVie, Bristol-Myers Squibb, Celgene, Eli Lilly and Company, Gilead, Janssen, MSD, Novartis, Pfizer Inc, Roche, Sanofi, UCB, Consultant of: AbbVie, Bristol-Myers Squibb, Celgene, Eli Lilly, Gilead, Janssen, MSD, Novartis, Pfizer Inc, Roche, Sanofi, UCB, Speakers bureau: AbbVie, Bristol-Myers Squibb, Celgene, Eli Lilly, Gilead, Janssen, MSD, Novartis, Pfizer Inc, Roche, Sanofi, UCB, Josef S. Smolen Grant/research support from: AbbVie, AstraZeneca, Celgene, Celltrion, Chugai, Eli Lilly, Gilead, ILTOO, Janssen, Novartis-Sandoz, Pfizer Inc, Samsung, Sanofi, Consultant of: AbbVie, AstraZeneca, Celgene, Celltrion, Chugai, Eli Lilly, Gilead, ILTOO, Janssen, Novartis-Sandoz, Pfizer Inc, Samsung, Sanofi, Philip J Mease Grant/ research support from: Abbott, Amgen, Biogen Idec, BMS, Celgene Corporation, Eli Lilly, Novartis, Pfizer, Sun Pharmaceutical, UCB - grant/research support, Consultant of: Abbott, Amgen, Biogen Idec, BMS, Celgene Corporation, Eli Lilly, Novartis, Pfizer, Sun Pharmaceutical, UCB - consultant, Speakers bureau: Abbott, Amgen, Biogen Idec, BMS, Eli Lilly, Genentech, Janssen, Pfizer, UCB speakers bureau, Enrique Soriano Grant/research support from: AbbVie, Eli Lilly, GlaxoSmithKline, Novartis, Pfizer Inc, Sandoz, Consultant of: AbbVie, Eli Lilly, 